\title{
Effect of Genetic Variants, Especially CYP2C9 and VKORC1, on the Pharmacology of Warfarin
}

\author{
Erik Fung, MB, ChB, PhD ${ }^{1,2}$, Nikolaos A. Patsopoulos, MD, PhD ${ }^{3,4,5}$, Steven M. Belknap, \\ MD $^{6}$, Daniel J. O’Rourke, MD ${ }^{1,2,7}$, John F. Robb, MD ${ }^{1,2}$, Jeffrey L. Anderson, MD ${ }^{8,9}$, \\ Nicholas W. Shworak, MD, PhD ${ }^{1,2,10}$, and Jason H. Moore, PhD ${ }^{2,11,12}$ \\ ${ }^{1}$ Section of Cardiology, Heart \& Vascular Center, Dartmouth-Hitchcock Medical Center, Lebanon, \\ New Hampshire \\ ${ }^{2}$ Geisel School of Medicine at Dartmouth, Dartmouth College, Hanover, New Hampshire \\ ${ }^{3}$ Department of Neurology, Brigham andWomen's Hospital, Harvard Medical School, Boston, \\ Massachusetts \\ ${ }^{4}$ Division of Genetics, Department of Medicine, Brigham and Women's Hospital, Harvard Medical \\ School, Boston, Massachusetts \\ ${ }^{5}$ Broad Institute of Harvard and MIT, Cambridge, Massachusetts \\ ${ }^{6}$ Department of Medicine, Northwestern Feinberg School of Medicine, Northwestern Memorial \\ Hospital, Chicago, Illinois \\ ${ }^{7}$ Section of Cardiology, Veterans Affairs Medical Center, White River Junction, Vermont \\ ${ }^{8}$ Cardiovascular Department, Intermountain Medical Center, Murray, Utah \\ ${ }^{9}$ University of Utah School of Medicine, Salt Lake City, Utah \\ ${ }^{10}$ Department of Pharmacology and Toxicology, Geisel School of Medicine at Dartmouth, \\ Dartmouth College, Hanover, New Hampshire \\ ${ }^{11}$ Institute of Quantitative Biomedical Science, Dartmouth College, Hanover, New Hampshire \\ ${ }^{12}$ Departments of Genetics and Community and Family Medicine, Geisel School of Medicine at \\ Dartmouth, Dartmouth College, Hanover, New Hampshire
}

\section{Abstract}

The genes encoding the cytochrome P450 2C9 enzyme (CYP2C9) and vitamin K-epoxide reductase complex unit 1 (VKORCl) are major determinants of anticoagulant response to warfarin. Together with patient demographics and clinical information, they account for approximately onehalf of the warfarin dose variance in individuals of European descent. Recent prospective and randomized controlled trial data support pharmacogenetic guidance with their use in warfarin dose initiation and titration. Benefits from pharmacogenetics-guided warfarin dosing have been

Copyright $(2012$ by Thieme Medical Publishers, Inc.

Address for correspondence and reprint requests Erik Fung, MB, ChB, PhD, Section of Cardiology, Heart \& Vascular Center, Dartmouth-Hitchcock Medical Center, One Medical Center Drive, Lebanon, New Hampshire 03756 (erik.fung @ hitchcock.org) 
reported to extend beyond the period of initial dosing, with supportive data indicating benefits to at least 3 months. The genetic effects of VKORCl and CYP2C9 in African and Asian populations are concordant with those in individuals of European ancestry; however, frequency distribution of allelic variants can vary considerably between major populations. Future randomized controlled trials in multiethnic settings using population-specific dosing algorithms will allow us to further ascertain the generalizability and cost-effectiveness of pharmacogenetics-guided warfarin therapy. Additional genome-wide association studies may help us to improve and refine dosing algorithms and potentially identify novel biological pathways.

\section{Keywords}

Warfarin; pharmacogenetics; polymorphisms; personalized medicine

Warfarin remains one of the most effective anticoagulants indicated for the treatment and prophylaxis of a range of prothrombotic cardiovascular, cerebrovascular, and hematologic conditions..$^{1-3}$ Although the cost-effectiveness and long-term safety of the latest generation of oral anticoagulants (e.g., dabigatran, rivaroxaban, apixaban) have become a subject of intense debate recently, warfarin continues to be the mainstay of anticoagulation after over six decades in clinical use. ${ }^{4,5}$ Tens of millions of patients use warfarin worldwide, and there are over two million warfarin users in the United States with over 30 million prescriptions dispensed in 2004 alone. ${ }^{6,7}$ Due to the wide interindividual variability and narrow therapeutic index of warfarin, ${ }^{8-10}$ there has been considerable interest in identifying genetic and nongenetic variables that affect warfarin dose requirements. ${ }^{11-14}$

Initially developed to accelerate the rate with which therapeutic levels of anticoagulation were achieved, fixed-dose algorithms have successively been superseded by more sophisticated clinical algorithms based on patient demographics and other clinical variables ${ }^{15}$; however, the success in ameliorating variability has been modest. Recently, pharmacogenetic testing of candidate genes important in warfarin pharmacodynamics (e.g., vitamin K-epoxide reductase complex unit 1 [VKORC1]) and pharmacokinetics (e.g., the cytochrome P450 2C9 enzyme [CYP2C9]) have yielded encouraging results in dose initiation and titration, ${ }^{16-18}$ with potential for cost savings and reduction of length of hospitalization. ${ }^{19}$ Several pharmacogenetics-guided dosing algorithms incorporate clinical variables and patient demographics and have compared favorably with clinical data-only algorithms. ${ }^{17,19-22}$ These studies have collectively contributed to the construction of a prototypical framework for translating genetics and physiologic phenotypes into clinical practice, to our improved understanding of human diversity, and to the advancement of genetics-guided personalized medicine.

Developed from decades of international collaboration, international normalized ratio (INR) as a standardized measurement of prothrombin time has served as the cornerstone for warfarin-related genetic studies and enabled comparisons between laboratories and different types of studies. Understanding how INR is derived is crucial because it represents the phenotype with which genes and variants are correlated. Concerted international efforts have recently revealed the differential contribution of genetic variants and transracial difference 
in warfarin dose requirements across ethnic groups and populations. ${ }^{12,23,24}$ For instance, although $V K O R C 1$ and $C Y P 2 C 9$ together with clinical variables and patient demographic information have been estimated to explain 40 to $50 \%$ of warfarin variability in individuals of European descent, their effects are often markedly less in warfarin users of Asian, African, Latin American, and other ancestry. ${ }^{14,21,23,25,26}$ These ethnic differences are of clinical importance with scientific and public health implications, given the increasing admixture and migration of populations worldwide with globalization. ${ }^{27,28}$

In this review, we discuss the definition of INR as a phenotypic correlate; the published evidence for the major genetic determinants, $V K O R C 1$ and $C Y P 2 C 9$, in influencing warfarin dose requirements in Europeans, Africans, Asians, and other ethnic groups; the clinical science and utility of VKORC1 and CYP2C9; and other genetic variants that affect the pharmacology of warfarin based on evidence from candidate gene and genome-wide association studies (GWAS).

\section{International Normalized Ratio}

Studies designed to investigate genetic determinants of warfarin dose requirements, pharmacogenetics-guided dosing of warfarin, and genome-wide quantitative trait mapping of dose variations have taken advantage of INR as a standardized measurement of the anticoagulant response to warfarin. INR is the ratio of the prothrombin time of a patient (test) sample to a normal reference value (the mean of normal values, or Mean Normal PT, MNPT) raised to the power of the international sensitivity index (ISI): $\left(\mathrm{PT}_{\text {test }} / \mathrm{PT}_{\text {reference }}\right)^{\mathrm{ISI}}$. Prothrombin time is assayed by applying tissue factor-containing thromboplastin to plasma with the addition of excessive calcium to reverse the chelating effects of citrate in the sample; the time for a sample to clot is the prothrombin time. The ISI value is supplied by the manufacturer of an analytical system, and adjusts for reagent batch variability against a standardized panel of control reagents endorsed by the World Health Organization. ${ }^{29}$ Periodic calibration of analytical instruments and the use of standardized assaying reagents are essential for reliable INR testing. Since its introduction in the 1970s, the normalization process has undergone several revisions. ${ }^{23,30}$

INR measures the extent of anticoagulation induced by warfarin. As a vitamin $\mathrm{K}$ antagonist, warfarin inhibits the production of functional forms of specific vitamin K-dependent clotting factors, including factors VII, IX, X, and II/prothrombin. Factor VII in the coagulation cascade is also the chief clotting factor activated by tissue factor in thromboplastin that triggers subsequent activation of factor IX, factor X, and prothrombin. Although INR is in general relatively robust, it represents an artificial surrogate measurement of warfarin anticoagulation reversible by exogenous tissue factor in vitro.

\section{Warfarin Dosing in the Absence of Genetic Information}

Following the development of standardized monitoring of anticoagulation with warfarin, it became apparent that fixed-dose loading regimens (e.g., $10 \mathrm{mg}$ on each of the first three consecutive days followed by subsequent dose titration) were unreliable, often resulting in over-anticoagulation in up to $35 \%$ of patients and prolonged hospitalization in those underanticoagulated. ${ }^{31}$ Continual efforts led to the further refinement of algorithms and tailored 
dosing schedules with later incorporation of patient demographics (e.g., age, weight) and

clinical data (e.g., albumin levels) adaptable for use in inpatient or outpatient settings. ${ }^{15,31-35}$ Adjusted-dose warfarin therapy was found to be superior to fixed-dose warfarin (plus aspirin) therapy, particularly evident in prospective, randomized clinical trials for the prevention of stroke in patients with atrial fibrillation. ${ }^{1,36}$ Despite these advances, a considerable degree of uncharacterized variability still existed, and studies aimed at delineating these variables ensued. ${ }^{13,37}$

Of variables that affect warfarin dose variance, age accounts for $7 \%$ and its effects have been found consistent in different studies and validated across ethnic groups. ${ }^{13,38-41}$ Flexible dosing protocols have been developed that adjust for age. ${ }^{34}$ Nongenetic, complex environmental variables including drug and food interactions, serum vitamin $\mathrm{K}$ levels, and clinical factors (e.g., renal and hepatic function, presence of malignancy), among others, have been correlated in some studies. ${ }^{37,42,43}$ Depending on the study population, clinical factors may explain up to $20 \%$ of warfarin dose requirements. ${ }^{44}$ However, the common, large interindividual dose requirements (e.g., in one study ranging from 7 to $280 \mathrm{mg}$ per week ${ }^{45}$ ) is not explained cumulatively by the majority of these uncommon though plausible factors with modest effect size. For instance, amiodarone can reduce warfarin dose requirement by approximately $18 \%{ }^{38}$ but is used by $<10 \%$ of warfarin users, and in a principal component analysis of 245 patients, of whom 21 took amiodarone, it was not found to be a statistically significant determinant. ${ }^{13}$ Of 94 predictor variables analyzed in one study, age and pharmacogenetic variables were found to be the strongest determinants of warfarin dose requirements. ${ }^{13}$

\section{Molecular Genetics, Polymorphisms, and Functions of CYP2C9 and VKORC1 \\ CYP2C9}

Warfarin is a coumarin derivative that exists as a racemic mixture of $S$ - and $R$-enantiomers. The former has about three times the potency of the latter, and the cytochrome P450 enzyme, CYP2C9, is responsible for metabolism of the $S$-enantiomer. ${ }^{6,46,47}$ CYP2C9 is considered one of the most important P450 enzymes in the liver responsible for metabolizing xenobiotics and a host of clinically important drugs, including antiinflammatory agents, oral hypoglycemic, oral anticoagulants, and diuretics. ${ }^{48}$

CYP2C9 is located on chromosome $10 \mathrm{q} 24$ spanning approximately $55 \mathrm{~kb}$ and contains nine exons. ${ }^{49}$ Following reports that multiple cDNA sequences of $C Y P 2 C 9$ were cloned to suggest a high level of polymorphism in the gene, ${ }^{49}$ the search for allelic variants was spurred on. The convention of the nomenclature for CYP2C9 is such that * number) denotes the variant allele with reference to $C Y P 2 C 9^{*} 1$, the wild-type or major allele with the amino acid sequences (Arg144/Tyr356//le359/Gly417) first identified in Northern Europeans. ${ }^{6,12}$ In this population, the allele frequency of $C Y P 2 C 9 * 2(\mathrm{R} 144 \mathrm{C}$; rs 1799853) and $C Y P 2 C 9 * 3$ was 12.5 and $8.5 \%$, respectively. ${ }^{50}$ Functional significance of the allelic variants $C Y P 2 C 9 * 2$ in exon 3 and $C Y P 2 C 9 * 3$ (I359L; rs 1057910) in exon 7 was demonstrated in expression assays in vitro, providing evidence that both reduced-function variants resulted in impaired 
metabolism of $S$-warfarin..$^{51,52}$ Respectively, enzymatic activity was reduced by approximately 30 and $80 \%,{ }^{17}$ and warfarin dose requirement was reduced by 14 to $20 \%$ and 21 to $49 \% .^{12,53,54}$ Modeling data from 137 patients suggested that through effects on rates of drug clearance $C Y P 2 C 9 * 2$ and $C Y P 2 C 9 * 3$ predicted $58 \%$ of warfarin dose variation based on the measured plasma $S$-warfarin concentration after initiation of warfarin therapy. ${ }^{55}$ Although both variants were also found to correlate with an increased risk of bleeding complications, ${ }^{17,53,56-60}$ neither stability of INR nor likelihood of severe overanticoagulation was associated. ${ }^{54}$

CYP2C9*4 was first reported in the Japanese population and associated also with reduced warfarin dose requirements. ${ }^{61}$ Studies on individuals of African descent revealed a host of other $C Y P 2 C 9$ variants not (commonly) found in individuals of European descent, including CYP2C9*5 (rs28371686), CYP2C9*6 (rs9332131), CYP2C9*8 (rs7900194), and $C Y P 2 C 9 * 11$ (rs28371685), among others, that impact on warfarin dose requirements. ${ }^{25,62-64} C Y P 2 C 9 * 14$ through $C Y P 2 C 9 * 19$ were discovered in a cohort of Southeast Asians from Singapore. ${ }^{65}$ There are at least 35 alleles of $C Y P 2 C 9$ documented ${ }^{6}$; however, the effects of the majority of these alleles on warfarin metabolism and dose requirements are yet to be characterized at present.

\section{VKORC1}

Vitamin $\mathrm{K}$ is an essential lipid-soluble micronutrient required for maintaining the equilibrium of hemostasis and is available to humans from the gut microflora and dietary intake of certain plants. ${ }^{66}$ As such, dietary variation, metabolic factors, and exposure to certain antibiotics and environmental factors can impact on warfarin anticoagulation. ${ }^{67}$ Factors VII, IX, X, and prothrombin are vitamin $\mathrm{K}$-dependent clotting factors that play central roles in the coagulation cascade as discussed earlier. Proper functioning of these factors requires posttranslational modification of glutamate side chains to $\gamma$ carboxyglutamate catalyzed by $\gamma$-glutamyl carboxylase (gene encoded by GGCX) ${ }^{66}$ Reduced coagulant activity results when these proteins are partially $\gamma$-carboxylated or decarboxylated. ${ }^{68,69}$ The process of $\gamma$-carboxylation is dependent on vitamin $\mathrm{K}$, a cofactor that interchanges from the reduced (active) to the epoxide (inactive) state while glutamate is converted to $\gamma$-carboxyglutamate. Recycling of the epoxide (vitamin K-2,3-epoxide) to the reduced (vitamin $\mathrm{K}$ hydroquinone) form is catalyzed by vitamin $\mathrm{K}$-epoxide reductase (VKOR) and inhibitable by warfarin (or other coumarin derivatives such as phenprocoumon). ${ }^{70}$ The VKOR complex unit 1 (VKORC1) is an 18 -kDa protein located in the endoplasmic reticulum ${ }^{70}$ and is expressed abundantly in hepatocytes. ${ }^{71}$

Through positional cloning ${ }^{72}$ and a siRNA gene knockdown approach, ${ }^{73}$ VKORCl was localized to chromosome 16p11.2. VKORCl consists of 5,125 base pairs and comprises three exons. ${ }^{70}$ Loss-of-function mutations in VKORCl can result in bleeding tendency, whereas warfarin resistance can also stem from mutations in VKORC1. ${ }^{66,70,72,74} \mathrm{In}$ exploring the functional significance of polymorphisms, studies have found expression of VKORC1 mRNA in several cell types and tissues, ranging from liver, myocardium, B lymphocytes to lung cancer cell lines. ${ }^{21,70,71,73}$ Imbalance in allelic expression of VKORC1 (allelic mRNA:DNA) attributable to a regulatory polymorphism (3730A > G, rs9284) at the 
$3^{\prime}$-UTR of VKORC1 was demonstrated in human liver specimens. ${ }^{71}$ Moreover, both the common, noncoding VKORCl single nucleotide polymorphisms (SNPs), $-1639 \mathrm{G}>\mathrm{A}$ and $1173 \mathrm{C}>\mathrm{T}$, exhibited dose-dependent allele-specific effects on VKORC1 mRNA levels, ${ }^{71}$ and $V K O R C 1$ genotype is predictive of plasma $S$-warfarin concentration required to yield therapeutic INR ${ }^{55}$ as well as the maintenance dose before initiation of therapy. ${ }^{75}$ These findings extended the graded gene/haplotype-dose effect observed in the DNA transcript analysis of haplotype groups A (associated with low dose of warfarin) and B (associated with high dose of warfarin) incorporating the earlier SNPs that Rieder et al constructed in their study. ${ }^{21}$ The $-1639 \mathrm{G}>\mathrm{A}$ and $1173 \mathrm{C}>\mathrm{T}$ polymorphisms are often tested interchangeably in pharmacogenetic studies due to their complete linkage disequilibrium (LD) with one another. ${ }^{6,76}$ Several SNPs associated with warfarin resistance including the amino acid-changing (nonsynonymous) $106 \mathrm{G}>\mathrm{T}$ (Arg36Tyr) variant ${ }^{77}$ and others have been reported. ${ }^{74,78,79}$

\section{CYP2C9 and VKORC1 in Dose Initiation and Titration}

The pharmacogenetic utility of $C Y P 2 C 9$ and VKORC1 during warfarin therapy has been examined in different clinical settings and populations over the last decade. Studies have established that CYP2C9 and VKORC1 genotypes conjointly influence warfarin dose requirements with impact on clinically significant endpoints and adverse events such as bleeding complications. ${ }^{17,21,22,56,58,59,76,80-85}$ Several metrics have been used to measure the strength, accuracy, and safety of pharmacogenetic guidance including time to therapeutic INR, time to stable INR, percentage of time in the therapeutic range (\%TTR), and percentage of out-of-range (\%OOR) INR in comparison with fixed-dose (empirical) regimens. ${ }^{16-18}$ However, a uniform standard of comparison between studies is lacking.

In a review published in 2009, Moyer et al summarizes well the literature on CYP2C9 and VKORC1 alleles and haplotypes, their prevalence across the three major races (individuals of European, Asian, and African descent), the mean dose requirements stratified by race and allele/haplotype, and the combined effects of $C Y P 2 C 9$ and $V K O R C l$ on mean dose requirements as a guidance for dose prescription. ${ }^{46}$ Since that time, tens of studies on subjects of different ancestry correlating with CYP2C 9 and VKORC1 alleles have been published. The next section of this review article extends that summary and continues the discussion on multiethnic differences in allele distribution and warfarin dose requirements (see below).

To date, over a dozen pharmacogenetics-guided warfarin dosing algorithms incorporating clinical and demographic information have been published, and a host of others specify various modifications depending on the study objectives and populations examined. ${ }^{42,86,87}$ Notable examples include the International Warfarin Pharmacogenetics Consortium (IWPC), ${ }^{20}$ Warfarin Genetic study in Sweden (WARG), ${ }^{26}$ CoumaGen, ${ }^{16} \mathrm{http} / / /$ www.warfarindosing.org, ${ }^{42}$ Warfarin Regimen using A Pharmacogenetics-guided Initiation Dosing (WRAPID), ${ }^{18}$ and Newcastle ${ }^{22}$ algorithms. A pharmacogenetics-guided dosing algorithm consists of a regression equation for calculating the warfarin initiation dose, an institutional protocol for INR-guided dose adjustment during the maintenance phase, and a timeline for specifying the dose initiation, maintenance, and follow-up intervals. The 
regression equation typically includes the following component variables: (1) patient demographics (e.g., age, height, weight), (2) clinical information (e.g., interacting medications, comorbidities), and (3) genetic information. These variable are factored into the calculation of the warfarin dose. ${ }^{87}$

The majority of warfarin dose prediction, algorithm development, modeling, and comparison studies are retrospective. ${ }^{6,46,86,88-96}$ Putting algorithms and dose prediction modeling into practice, prospective studies are still scarce, but the numbers are increasing. ${ }^{16-18,26,97-102}$ In the recently published prospective WRAPID study, 167 patients were initiated on warfarin for atrial fibrillation or venous thromboembolism using a newly developed pharmacogenetics algorithm incorporating patient demographics and clinical and genetic information (VKORC1, CYP2C $9 * 2$ and $* 3$ ) for initial dose loading and maintenance dosing. ${ }^{18}$ Although the study lacked a control group, it demonstrated the clinical utility and safety of pharmacogenetics guidance in determining loading and maintenance doses by the lack of genotype-specific differences in time to first therapeutic INR and risk of overanticoagulation (INR > 4) even after adjusting for covariates.

The first prospective, randomized, controlled trial (CoumaGen) by Anderson et al compared standard empirical dosing versus pharmacogenetic guidance in 206 patients and concluded that pharmacogenetic-guided warfarin dose initiation more accurately and efficiently approximated stable doses. ${ }^{16} \mathrm{~A}$ statistical significance in the primary end point of $\% \mathrm{OOR}$ INR was not observed between the two arms (possibly due to insufficient power), but significance observed in exploratory analyses comparing wild-type and multiple variant carriers prompted the launch of the CoumaGen-II study. ${ }^{17}$ The CoumaGen-II study comprised comparisons of primary end points at 30 days and up to 3 months of $\%$ OOR INRs and \%TTR between two groups in two arms. The first arm ( $n=504$ patients) compared a modified IWPC pharmacogenetics algorithm (PG-1) against one in which use of CYP2C9 genotype information was deferred until after day 2 (based on the premise of the pharmacokinetics of warfarin) plus the use of a dose-revision algorithm (PG-2) with the goal of maximizing approximation of the initiation dose to the stable maintenance dose. The second arm ( $n=2,343$ patients) compared PG-1/PG-2 against the standard parallel controls consisting of patients being initiated on an empirical dose of warfarin (usually, $5 \mathrm{mg} / \mathrm{d}$ ). Following initiation (from day 8 onwards), the institutional chronic anticoagulation clinic's warfarin maintenance dosing protocol was applied to both arms. The sufficiently powered study found no statistical difference in end points between PG-1 and PG-2 groups to suggest superiority of either algorithm, and thus, both were combined as a PG cohort in the second arm comparison against the standard dosing controls. The latter comparison saw highly significant differences in the prespecified primary end points (\%OOR INRs and \%TTR), as well as some secondary end points including average percent INRs $\geq 4$ or $\leq 1.5$, and average percent INRs $\leq 1.5 .{ }^{17}$ As a metric of anticoagulation clinic quality (US national average of $\%$ TTR is approximately 50 to $60 \%$ ), patient's compliance, longitudinal dosing stability, and, more importantly, a measure of therapeutic benefits (e.g., protection from stroke in patients with atrial fibrillation) derived from warfarin anticoagulation, ${ }^{103}$ the \%TTR conferring a > $10 \%$ (TTR from 58.4 to $68.9 \%$ at 30 days, and from 58.6 to $71.2 \%$ ) improvement with pharmacogenetic guidance is remarkable. Clinical effectiveness of pharmacogenetic 
guidance in dose initiation and titration has also previously been demonstrated in the prospective, nonrandomized Medco-Mayo study. ${ }^{19}$ Intriguingly, there is a growing consensus that the lasting benefits of pharmacogenetic guidance extend beyond 1 week of warfarin therapy. ${ }^{17,104}$ Other relatively small (sample size of around or fewer than 200 patients) prospective studies with or without randomization have reported mixed or negative results, possibly related to the study design, power, differences in patient populations, or other factors. ${ }^{105,106}$ Several large, randomized clinical trials (e.g., COAG, GIFT, EU-PACT) approaching or exceeding 1,000 patients are ongoing 107 that should help to address questions not answered by available studies.

\section{Interethnic Variability and Distribution of CYP2C9, VKORC1 and Other}

\section{Variants}

Race and ethnicity are recognized determinants of warfarin dose requirements. ${ }^{108-110}$ African ancestry generally confers the highest adjusted mean weekly warfarin dose (43 mg, range: 39 to $47 \mathrm{mg}$ ) compared with their European ( $36 \mathrm{mg}$, 34 to $39 \mathrm{mg}$ ), Latin American (31 mg, 25 to $37 \mathrm{mg}$ ), and Asian ( $24 \mathrm{mg}, 21$ to $27 \mathrm{mg}$ ) counterparts. ${ }^{38}$ The African population is also the most genetically diverse and heterogeneous. ${ }^{111}$

Dose variability attributable to genetics is less well captured in non-Europeans, especially Asians and Africans. ${ }^{24}$ Featuring VKORC1, CYP $2 C 9 * 2$ and $C Y P 2 C 9 * 3$ variants, and clinical information, the IWPC algorithm that was developed from an international panel of approximately 5,000 patients consistently performed well in individuals of European descent demonstrating approximately 50 to $65 \%$ or higher of dose variability with accuracy in the range of 10 to $20 \%$ of maintenance dose. ${ }^{20,24,112}$ However, only about 30 to $40 \%$ (range: 8 to $46 \%$ ) dose variance is explained in non-European populations depending on the study, ${ }^{92,112-114}$ and suggests the inadequacy of VKORC1, CYP2C $9^{*} 2$, and $C Y P 2 C 9^{*} 3$, or missing pharmacogenetic information for non-Europeans.

\section{Warfarin Users of African Descent}

An analysis of VKORCl distribution has shown a haplotype $\mathrm{A}^{21}$ frequency of $10.6 \%$ in African American $(n=273)$ and $35 \%$ in European-Americans $(n=302) .{ }^{115}$ In general, VKORC1 and CYP2C9 variants account for upward of 30 to $40 \%$ of dose variance, even with incorporation of clinical information in individuals of African descent, ${ }^{112,114-116}$ and depending on the number of CYP2C9 variants included in the analysis. ${ }^{25} \mathrm{In}$ an analysis using the IWPC dosing algorithm that derived a $29 \%$ dose variance in a study population of African Americans, ${ }^{112}$ addition of the CYP2C 9 variants $C Y P 2 C 9 * 6$ (rs90449157), CYP2C $9 * 8$ (rs90442184), and CYP2C $9 * 11$ (rs90481096) (all rare in Europeans) improved the variance explained to $41 \% .{ }^{112}$ In a study of warfarin clinic subjects with discrepant therapeutic and algorithm-predicted doses, Scott et al demonstrated in one African American patient on a lower-than-expected dose $(14.4 \mathrm{mg} / \mathrm{wk})$ the failure of 15 published algorithms to accurately predict the required dose (a mean recommended dose of $41.8 \mathrm{mg} / \mathrm{wk}$, range: 24.9 to $52.2 \mathrm{mg} / \mathrm{wk}$ ). ${ }^{25}$ The study pointed out the potential utility of $C Y P 2 C 9 * 8$ (rs7900194; allele frequency of 0.047) in African American and recommended its inclusion in conjunction with $C Y P 2 C 9 * 2, C Y P 2 C 9 * 3, C Y P 2 C 9 * 5, C Y P 2 C 9 * 6$, and $C Y P 2 C 9 * 11$ 
(combined allele frequency of 0.133 ) for improved dose predictability. ${ }^{25}$ Further support in using $C Y P 2 C 9 * 8$ for warfarin dose prediction in Africans has come from a study on 213 South African blacks, ${ }^{117}$ and another on 226 African American that illustrated improvement of the percent dose variance explained to approximately 30 to $36 \%$ with clinical variables and VKORC1-1639G $>$ A. ${ }^{62}$

Heterogeneity of the African race is evident in a study on 993 Africans that examined 14 SNPs in seven genes previously reported to influence warfarin dosage. ${ }^{118}$ Comparing the different native African populations with migrant individuals of Asian and European ancestry in South Africa, CYP2C $9 * 2$ was found to be monomorphic and VKORC1 SNPs had low variant allele frequencies ( 0.03 to 0.04$)$ in the Africans, indicating limited utility of those variants in South African blacks. Nonetheless, differences in allele frequencies of the panel of SNPs tested have enabled the differentiation of ancestral lineage among the African subpopulations, including native South Africans, Massai Kenyans, Luhya Kenyans, and Yoruba Nigerians; close affinity was unexpectedly observed between the latter two populations. ${ }^{118}$ In a study of individuals with warfarin resistance, the VKORC1 Asp36Tyr variant initially identified in Jewish individuals of Ethiopian (allele frequency of 15\%) and Ashkenazi (4\%) origins was reportedly common in 154 Ethiopian blacks (also with an allele frequency of $15 \%) .{ }^{119}$ The great level of genetic heterogeneity, extensive population substructure, and less LD in the African population compared with other races ${ }^{111}$ explains the difficulties in analyzing individuals of African descent, and demands close attention to their characterization.

\section{Warfarin Users of Asian Descent}

East Asians typically require on average about 3.0 to $4.0 \mathrm{mg} / \mathrm{d}$, or about 21 to $28 \mathrm{mg} / \mathrm{wk}$, of warfarin to achieve therapeutic INR. ${ }^{38,120-122} \mathrm{~A}$ VKORCl haplotype analysis comparing five East Asian populations (Han Chinese from Taiwan and China, individuals from Indonesia, the Philippines, Thailand, and Vietnam) with a South Asian population (Indians residing in Taiwan) totaling 553 patients reported relatively close similarities in variant frequencies among East Asians, but significant differences were observed when compared with Indians. ${ }^{123}$ Allele frequencies of the wild-type CYP $2 C 9^{*} 1$ and the VKORC1 $1173 \mathrm{C}>\mathrm{T}$ variant found commonly in East Asians (allele frequencies of $>0.90$ and 0.8 to 0.9, respectively) are similar among the Chinese, ${ }^{23}$ Japanese, ${ }^{120}$ and Koreans. ${ }^{124}$ At the subpopulation level, the Bai, Tibetan, and Han Chinese ethnic groups also displayed similar VKORC1 3673G > A allele frequencies of 92.8, 90.2, and 90.8\%, respectively, for the A allele. ${ }^{125}$ An allele-specific, graded dose effect in accordance with the $C Y P 2 C 9$ and VKORC1 genotypes is seen in Asians as for the well-studied European populations. ${ }^{23,126}$ Whereas the African populations have in general a repertoire of reduced-function $C Y P 2 C 9$ variants (e.g., $C Y P 2 C 9 * 5, C Y P 2 C 9 * 6, C Y P 2 C 9 * 8, C Y P 2 C 9 * 11$ ) that influence warfarin dose response, ${ }^{25,112,117}$ the relatively less heterogeneous East Asian populations have allele frequencies of $>90$ to $95 \%$ at the wild-type CYP2C*1, and frequencies of 80 to $90 \%$ at the reduced-function VKORCl variants (e.g., 1173TT, - 1639AA) that could explain their overall lower warfarin dose requirements compared with their African and European counterparts. ${ }^{110,124} \mathrm{By}$ far the single factor that explains the greatest proportion of dose variation is VKORCl, estimated at 20 to $30 \%$ from genotyping studies and GWAS, ${ }^{14}$ and is, 
hence, a main source for the reduced dose requirement in East Asians. Collectively, patient, clinical, and genetic information account for 40 to 50\% (mean: $48 \%$, range: 33.2 to $76.8 \%$, from 17 East Asian studies of dose variation explained. ${ }^{86,102,120,124,126-137}$

Multiethnic studies on Southeast Asians have shown greater similarity between Malaysians, Indonesians, Thais, and Chinese than with Indians. ${ }^{27,123,138-140}$ For instance, $C Y P 2 C 9 * 2$ is consistently absent in these Southeast Asian populations but present in up to $5.9 \%$ of Indians. ${ }^{141,142}$ The dose variance explained by CYP2C 9 and VKORC1 along with patient demographics and clinical data varied considerably from $15.4 \%$ in an Indonesian study, ${ }^{143}$ $36.5 \%$ in a Malaysian study, ${ }^{144}$ to $61 \%$ including $C Y P 4 F 2$ in a multiethnic Singaporean study. ${ }^{27}$

\section{Warfarin Users in Latin America, Other Regions, and Heterogeneous Populations}

Apart from indigenous individuals native to Central and South America (Native Americans) in whom a unique frequency distribution of VKORC1 SNPs is observed, ${ }^{145}$ immigrant populations such as Brazilians and Argentinians of European descent have allele frequencies and profiles that follow their native European counterparts. ${ }^{146,147}$ The direction of gene effects from allelic variants is congruent between the major populations and Hispanic Americans, Colombians, and Puerto Ricans. ${ }^{148-151}$ These effects were also found consistent in the Turkish, ${ }^{152,153}$ Lebanese, ${ }^{154,155}$ Omani, ${ }^{156}$ Iranian, ${ }^{156}$ Egyptian, ${ }^{157,158}$ and Jewish ${ }^{97,159}$ populations. Several of these populations exhibit allele frequencies intermediate between the major races (Africans, Asians, and Europeans), and appear in line with the human migration patterns and the bottleneck of the founding of non-African populations some 50,000 to 100,000 years ago as evidenced by lower genetic diversity, a considerably higher level of LD, and more similar patterns of LD. ${ }^{111}$

\section{Genomic Basis for CYP2C9 and VKORC1 as Determinants of Dose Variance and the Remaining Genetic Determinants}

Over the past 5 years, advances in high-throughput technologies have made feasible the agnostic interrogation of SNPs genome-wide. Currently, two GWAS on warfarin dosage have been published with individuals of European ancestry. ${ }^{11,14}$ Cooper et a ${ }^{11}$ genotyped approximately 500K SNPs in 181 subjects as a discovery phase and then replicated the best signals with a $p$ value of less than $10^{-4}$ in another 374 samples (Table 1). In the discovery phase, only SNPs in VKORC1 reached the study's level of genome-wide significance ( $p<$ $10^{-7}$ ), whereas polymorphisms in $C Y P 2 C 9$ were genome-wide significant post-replication. The next best signal was rs 2286461 near FGFBP2 on chromosome 4, which had a $p$ value of $6.6 \times 10^{-7}$ in the discovery set. However, the joint discovery and replication analysis yielded a $p$ value of $1.8 \times 10^{-5}$, suggesting that the effect in the discovery and replication sets were in opposite directions. The same was apparent for almost all the other regions that were selected for replication. One exception was rs 216013 in the intron of CACNAIC on chromosome 12, which reached a $p$ value of $8.6 \times 10^{-7}$ in the joint analysis, with a $p$ value of $9.2 \times 10^{-5}$ in the discovery set. VKORC1 and CYP $2 C 9$ explained 25 and $9 \%$ of the warfarin dose variance, respectively, whereas inclusion of nongenetic information (age, gender, treatment with amiodarone, treatment with losartan, and weight) increased the 
variance explained to $47 \%$. This study ${ }^{11}$ was underpowered to identify variants with small contribution to warfarin dose variance; for example, it had $80 \%$ power to detect a SNP association explaining $20 \%$ of the variance in warfarin dosing, which is almost the effect of VKORC1.

VKORC1 and CYP2C9 were also statistically significant in another GWAS of Swedish individuals. ${ }^{14}$ Takeuchi et al ${ }^{14}$ applied a two-stage approach with 1,053 subjects in the discovery set and 588 in the replication set (Table 1 ). The study had $80 \%$ power to identify a genetic variant explaining at least $1.5 \%$ of the warfarin dose variance. The minor alleles of both $V K O R C 1$ and $C Y P 2 C 9$ reported SNPs had protective effects on warfarin dose (i.e., carriers of the minor alleles required less warfarin), and the variance explained was $28.3 \%$ and $7.5 \%$, respectively. In the primary analysis, no other region reached the a priori defined level of genome-wide significance of $10^{-7}$. In a secondary analysis, the authors fitted a multivariate regression adjusting for the effects of VKORC1, CYP2C9, age, and sex, identifying rs2108622 in exon 2 of CYP4F2 on chromosome 19 at genome-wide level. The carriers of the minor allele had an increase of warfarin dose and thus an opposite effect of VKORC1 and CYP2C9 and explained around $1.5 \%$ of overall variance in the discovery set. The authors also investigated 2,530 copy number variants (CNVs); however, none of these were found to be associated with the warfarin dose. ${ }^{14}$ Corroborating those findings, a focused genotyping study of CNVs in CYP2C9, VKORC1, CYP4F2, GGCX, and CALU from 178 multiethnic patient samples (Americans of European, African, Latino, and Asian descent), in addition to 350 additional samples testing for CYP2C9 exon 8, found that all participants had two copies of the gene. ${ }^{45}$

Findings from GWAS on warfarin dose in Japanese individuals bore remarkable resemblance to those of their (European) counterparts. ${ }^{160}$ Cha et al split their discovery set into subjects with high and low warfarin dose and treated the phenotype as binary.

VKORC1, CYP2C9, and CYP4F2 affected warfarin dose in the same direction as in the European samples (Table 1). The effects of these 3 loci reportedly explained approximately $43 \%$ of the phenotypic variance in a replication set.

Interestingly, a GWAS of acenocoumarol maintenance dose in Europeans identified culprits in the same three regions. The strongest signal was in rs 10871454 in STX4A gene, which is in complete linkage disequilibrium $\left(r^{2}=1\right.$ and $\left.\mathrm{D}^{\prime}=1\right)$ with rs9923231 in VKORCl (Table 1). All three effects had the same direction as per the warfarin GWAS and could explain similar portions of the variance of acenocoumarol maintenance dose, highlighting the importance of these loci in anticoagulation therapy using a dicoumarol/coumarin derivative. Furthermore, this study found rs 1998591 in CYP2C18 to have a genome-wide effect $\left(p<5 \times 10^{-8}\right)$, while accounting for $\sim 1 \%$ of the acenocoumarol dose variance. Although published GWAS on warfarin dosage report no information on $C Y P 2 C 18$, polymorphisms in the same gene have been suggested to alter warfarin-related phenotypes in candidate gene studies. ${ }^{130,161}$

GWAS of warfarin dose have been relatively successful so far. Besides the strong effects in VKORC1 and CYP2C9, there is evidence that more genes could play a role, although with small effects. $C Y P 4 F 2$ is a notable example; because of its small contribution to variance explained $(\sim 1 \%)$, the underpowered GWAS by Cooper et al could not have identified it. 
Evidence from GWAS in other traits suggests that larger discovery sets and meta-analysis of GWAS can increase power and help identify variants with (very) small effects. ${ }^{162}$ Furthermore, none of the earlier GWAS has accounted for the effect of population stratification (differences in allelic frequencies between subpopulations) or reported the genomic inflation factor $(\lambda) .{ }^{163}$ Typically, population stratification can cause spurious associations; however, failure to account for population substructure can also cause loss of power to detect true effects. ${ }^{164}$

\section{Conclusions and Implications}

VKORCl and $C Y P 2 C 9$ in conjunction with patient demographics and clinical information explain about half of the dose variance in patients taking warfarin, particularly in individuals of European descent. Current evidence and existing pharmacogenetic and genomic data indicate that another one-half of dose variance is yet to be accounted for by genetic and nongenetic factors. Due to limitations of the previously performed GWAS, it remains unclear whether additional common, large-effect size genes similar to VKORC1 and CYP2C9 exist.

In the era of globalization, entry into health care systems is increasingly made by multiethnic and admixed populations, as evident in the patient population served by clinics and hospitals in major urban areas such as New York City, ${ }^{64}$ Toronto, ${ }^{28}$ Singapore, ${ }^{123}$ and others. The development and advances in warfarin pharmacogenetic testing is already serving as a prototypical framework for future developments to follow. The priority will stand with how best to deliver health care and medicines safely and effectively to diverse, multiethnic populations in an individualized manner, and pharmacogenetics will likely be a major contributor.

Globalization and the Information Age have accelerated access to technology, and delivered direct-to-consumer personalized genomic testing. ${ }^{165}$ Genetic/genomic data are already integrated with electronic medical record (EMR) system featuring capacity for clinical use. ${ }^{112}$ Using warfarin pharmacogenetic testing as an example, one could imagine the oneoff test results becoming available within 1 hour, ${ }^{17,166}$ ready for use at the time of warfarin initiation based on a personalized dosing algorithm, and then the pharmacogenetic data being stored in an EMR until future use when the latest variables (e.g., advancing age, new current medications, comorbidities) are updated and the warfarin dose calculated and dispensed automatically at no additional cost. In a cost-effectiveness analysis in 2009, it was suggested that if warfarin pharmacogenetics guidance could reduce the OOR INR by 5 to $9 \%$, then testing would be beneficial. ${ }^{167}$ In the latest prospective, randomized, controlled trial, pharmacogenetic guidance was found to increase the OOR INR by $12 \% .{ }^{17}$

\section{Acknowledgments}

The authors thank Professor Hau C. Kwaan, MD, PhD, for editorial guidance.

\section{References}

1. Stroke Prevention in Atrial Fibrillation Investigators. Adjusted-dose warfarin versus low-intensity, fixed-dose warfarin plus aspirin for high-risk patients with atrial fibrillation: Stroke Prevention in 
Atrial Fibrillation III randomised clinical trial. Lancet. 1996; 348(9028):633-638. [PubMed: 8782752]

2. Hart RG, Pearce LA, Aguilar MI. Meta-analysis: antithrombotic therapy to prevent stroke in patients who have nonvalvular atrial fibrillation. Ann Intern Med. 2007; 146(12):857-867. [PubMed: 17577005]

3. Petersen P, Boysen G, Godtfredsen J, Andersen ED, Andersen B. Placebo-controlled, randomised trial of warfarin and aspirin for prevention of thromboembolic complications in chronic atrial fibrillation. The Copenhagen AFASAK study. Lancet. 1989; 1(8631):175-179. [PubMed: 2563096]

4. Avorn J. The relative cost-effectiveness of anticoagulants: obvious, except for the cost and the effectiveness. Circulation. 2011; 123(22):2519-2521. [PubMed: 21606400]

5. Friberg L, Rosenqvist M, Lip GY. Net clinical benefit of warfarin in patients with atrial fibrillation: a report from the Swedish atrial fibrillation cohort study. Circulation. 2012; 125(19):2298-2307. [PubMed: 22514252]

6. Flockhart DA, O'Kane D, Williams MS, et al. Pharmacogenetic testing of CYP2C9 and VKORC1 alleles for warfarin. Genet Med. 2008; 10(2):139-150. [PubMed: 18281922]

7. Wysowski DK, Nourjah P, Swartz L. Bleeding complications with warfarin use: a prevalent adverse effect resulting in regulatory action. Arch Intern Med. 2007; 167(13):1414-1419. [PubMed: 17620536]

8. Hylek EM, Chang YC, Skates SJ, Hughes RA, Singer DE. Prospective study of the outcomes of ambulatory patients with excessive warfarin anticoagulation. Arch Intern Med. 2000; 160(11): 1612-1617. [PubMed: 10847254]

9. Merli GJ, Tzanis G. Warfarin: what are the clinical implications of an out-of-range-therapeutic international normalized ratio? J Thromb Thrombolysis. 2009; 27(3):293-299. [PubMed: 18392557]

10. Oake N, Jennings A, Forster AJ, Fergusson D, Doucette S, van Walraven C. Anticoagulation intensity and outcomes among patients prescribed oral anticoagulant therapy: a systematic review and meta-analysis. CMAJ. 2008; 179(3):235-244. [PubMed: 18663203]

11. Cooper GM, Johnson JA, Langaee TY, et al. A genome-wide scan for common genetic variants with a large influence on warfarin maintenance dose. Blood. 2008; 112(4):1022-1027. [PubMed: $18535201]$

12. Kamali F, Wynne H. Pharmacogenetics of warfarin. Annu Rev Med. 2010; 61:63-75. [PubMed: 19686083]

13. Skov J, Bladbjerg EM, Rasmussen MA, Sidelmann JJ, Leppin A, Jespersen J. Genetic, clinical and behavioural determinants of vitamin K-antagonist dose - explored through multivariable modelling and visualization. Basic Clin Pharmacol Toxicol. 2011; 67(11):1169-1174.

14. Takeuchi F, McGinnis R, Bourgeois S, et al. A genome-wide association study confirms VKORC1, CYP2C9, and CYP4F2 as principal genetic determinants of warfarin dose. PLoS Genet. 2009; 5(3):e1000433. [PubMed: 19300499]

15. Shine D, Patel J, Kumar J, et al. A randomized trial of initial warfarin dosing based on simple clinical criteria. Thromb Haemost. 2003; 89(2):297-304. [PubMed: 12574810]

16. Anderson JL, Horne BD, Stevens SM, et al. Randomized trial of genotype-guided versus standard warfarin dosing in patients initiating oral anticoagulation. Circulation. 2007; 116(22):2563-2570. [PubMed: 17989110]

17. Anderson JL, Horne BD, Stevens SM, et al. A randomized and clinical effectiveness trial comparing two pharmacogenetic algorithms and standard care for individualizing warfarin dosing (CoumaGen-II). Circulation. 2012; 125(16):1997-2005. [PubMed: 22431865]

18. Gong IY, Tirona RG, Schwarz UI, et al. Prospective evaluation of a pharmacogenetics-guided warfarin loading and maintenance dose regimen for initiation of therapy. Blood. 2011; 118(11): 3163-3171. [PubMed: 21725053]

19. Epstein RS, Moyer TP, Aubert RE, et al. Warfarin genotyping reduces hospitalization rates results from the MM-WES (Medco-Mayo Warfarin Effectiveness study). J Am Coll Cardiol. 2010; 55(25):2804-2812. [PubMed: 20381283] 
20. Klein TE, Altman RB, Eriksson N, et al. Estimation of the warfarin dose with clinical and pharmacogenetic data. N Engl J Med. 2009; 360(8):753-764. Erratum in N Engl J Med 2009; 361(16):1613. [PubMed: 19228618]

21. Rieder MJ, Reiner AP, Gage BF, et al. Effect of VKORC1 haplotypes on transcriptional regulation and warfarin dose. N Engl J Med. 2005; 352(22):2285-2293. [PubMed: 15930419]

22. Sconce EA, Khan TI, Wynne HA, et al. The impact of CYP2C9 and VKORC1 genetic polymorphism and patient characteristics upon warfarin dose requirements: proposal for a new dosing regimen. Blood. 2005; 106(7):2329-2333. [PubMed: 15947090]

23. Lam MP, Cheung BM. The pharmacogenetics of the response to warfarin in Chinese. Br J Clin Pharmacol. 2012; 73(3):340-347. [PubMed: 22023024]

24. Limdi NA, Wadelius M, Cavallari L, et al. Warfarin pharmacogenetics: a single VKORC1 polymorphism is predictive of dose across 3 racial groups. Blood. 2010; 115(18):3827-3834. [PubMed: 20203262]

25. Scott SA, Jaremko M, Lubitz SA, Kornreich R, Halperin JL, Desnick RJ. CYP2C9*8 is prevalent among African-Americans: implications for pharmacogenetic dosing. Pharmacogenomics. 2009; 10(8):1243-1255. [PubMed: 19663669]

26. Wadelius M, Chen LY, Lindh JD, et al. The largest prospective warfarin-treated cohort supports genetic forecasting. Blood. 2009; 113(4):784-792. [PubMed: 18574025]

27. Chan SL, Suo C, Lee SC, et al. Translational aspects of genetic factors in the prediction of drug response variability: a case study of warfarin pharmacogenomics in a multi-ethnic cohort from Asia. Pharmacogenomics J. 2011; 12(4):312-318. [PubMed: 21383771]

28. Shuen AY, Wong BY, Fu L, Selby R, Cole DE. Evaluation of the warfarin-resistance polymorphism, VKORC1 Asp36Tyr, and its effect on dosage algorithms in a genetically heterogeneous anticoagulant clinic. Clin Biochem. 2012; 45(6):397-401. [PubMed: 22266406]

29. Poller L. International Normalized Ratios (INR): the first 20 years. J Thromb Haemost. 2004; 2(6): 849-860. [PubMed: 15140114]

30. Kirkwood TB. Calibration of reference thromboplastins and standardisation of the prothrombin time ratio. Thromb Haemost. 1983; 49(3):238-244. [PubMed: 6879511]

31. Fennerty A, Dolben J, Thomas P, et al. Flexible induction dose regimen for warfarin and prediction of maintenance dose. Br Med J (Clin Res Ed). 1984; 288(6426):1268-1270.

32. Crowther MA, Harrison L, Hirsh J. Randomized trial of warfarin nomograms. Ann Intern Med. 2004; 140(6):490. [PubMed: 15023725]

33. Kovacs MJ, Rodger M, Anderson DR, et al. Comparison of 10-mg and 5-mg warfarin initiation nomograms together with low-molecular-weight heparin for outpatient treatment of acute venous thromboembolism. A randomized, double-blind, controlled trial. Ann Intern Med. 2003; 138(9): 714-719. [PubMed: 12729425]

34. Roberts GW, Druskeit T, Jorgensen LE, et al. Comparison of an age adjusted warfarin loading protocol with empirical dosing and Fennerty's protocol. Aust N Z J Med. 1999; 29(5):731-736. [PubMed: 10630656]

35. Tait RC, Sefcick A. A warfarin induction regimen for out-patient anticoagulation in patients with atrial fibrillation. Br J Haematol. 1998; 101(3):450-454. [PubMed: 9633885]

36. Li-Saw-Hee FL, Blann AD, Lip GY. Effects of fixed low-dose warfarin, aspirin-warfarin combination therapy, and dose-adjusted warfarin on thrombogenesis in chronic atrial fibrillation. Stroke. 2000; 31(4):828-833. [PubMed: 10753983]

37. Holbrook AM, Pereira JA, Labiris R, et al. Systematic overview of warfarin and its drug and food interactions. Arch Intern Med. 2005; 165(10):1095-1106. [PubMed: 15911722]

38. Dang MT, Hambleton J, Kayser SR. The influence of ethnicity on warfarin dosage requirement. Ann Pharmacother. 2005; 39(6):1008-1012. [PubMed: 15855242]

39. Gurwitz JH, Avorn J, Ross-Degnan D, Choodnovskiy I, Ansell J. Aging and the anticoagulant response to warfarin therapy. Ann Intern Med. 1992; 116(11):901-904. [PubMed: 1580446]

40. McClain MR, Palomaki GE, Piper M, Haddow JE. A rapid-ACCE review of CYP2C9 and VKORC1 alleles testing to inform warfarin dosing in adults at elevated risk for thrombotic events to avoid serious bleeding. Genet Med. 2008; 10(2):89-98. [PubMed: 18281915] 
41. Wynne HA, Kamali F, Edwards C, Long A, Kelly P. Effect of ageing upon warfarin dose requirements: a longitudinal study. Age Ageing. 1996; 25(6):429-431. [PubMed: 9003877]

42. Gage BF, Eby C, Johnson JA, et al. Use of pharmacogenetic and clinical factors to predict the therapeutic dose of warfarin. Clin Pharmacol Ther. 2008; 84(3):326-331. [PubMed: 18305455]

43. Jonas DE, McLeod HL. Genetic and clinical factors relating to warfarin dosing. Trends Pharmacol Sci. 2009; 30(7):375-386. [PubMed: 19540002]

44. Burmester JK, Berg RL, Glurich I, Yale SH, Schmelzer JR, Caldwell MD. Absence of novel CYP4F2 and VKORC1 coding region DNA variants in patients requiring high warfarin doses. Clin Med Res. 2011; 9(3-4):119-124. [PubMed: 21562135]

45. Scott SA, Patel M, Martis S, et al. Copy number variation and warfarin dosing: evaluation of CYP2C9, VKORC1, CYP4F2, GGCX and CALU. Pharmacogenomics. 2012; 13(3):297-307. [PubMed: 22188360]

46. Moyer TP, O'Kane DJ, Baudhuin LM, et al. Warfarin sensitivity genotyping: a review of the literature and summary of patient experience. Mayo Clin Proc. 2009; 84(12):1079-1094.

[PubMed: 19955245]

47. Rettie AE, Korzekwa KR, Kunze KL, et al. Hydroxylation of warfarin by human cDNA-expressed cytochrome P-450: a role for P-4502C9 in the etiology of (S)-warfarin-drug interactions. Chem Res Toxicol. 1992; 5(1):54-59. [PubMed: 1581537]

48. Rettie AE, Jones JP. Clinical and toxicological relevance of CYP2C9: drug-drug interactions and pharmacogenetics. Annu Rev Pharmacol Toxicol. 2005; 45:477-494. [PubMed: 15822186]

49. de Morais SM, Schweikl H, Blaisdell J, Goldstein JA. Gene structure and upstream regulatory regions of human CYP2C9 and CYP2C18. Biochem Biophys Res Commun. 1993; 194(1):194201. [PubMed: 8333835]

50. Stubbins MJ, Harries LW, Smith G, Tarbit MH, Wolf CR. Genetic analysis of the human cytochrome P450 CYP2C9 locus. Pharmacogenetics. 1996; 6(5):429-439. [PubMed: 8946475]

51. Haining RL, Hunter AP, Veronese ME, Trager WF, Rettie AE. Allelic variants of human cytochrome P450 2C9: baculovirus-mediated expression, purification, structural characterization, substrate stereoselectivity, and prochiral selectivity of the wild-type and I359L mutant forms. Arch Biochem Biophys. 1996; 333(2):447-458. [PubMed: 8809086]

52. Rettie AE, Wienkers LC, Gonzalez FJ, Trager WF, Korzekwa KR. Impaired (S)-warfarin metabolism catalysed by the R144C allelic variant of CYP2C9. Pharmacogenetics. 1994; 4(1):3942. [PubMed: 8004131]

53. Margaglione M, Colaizzo D, D'Andrea G, et al. Genetic modulation of oral anticoagulation with warfarin. Thromb Haemost. 2000; 84(5):775-778. [PubMed: 11127854]

54. Taube J, Halsall D, Baglin T. Influence of cytochrome P-450 CYP2C9 polymorphisms on warfarin sensitivity and risk of over-anticoagulation in patients on long-term treatment. Blood. 2000; 96(5): 1816-1819. [PubMed: 10961881]

55. Linder MW, BonHomme M, Reynolds KK, et al. Interactive modeling for ongoing utility of pharmacogenetic diagnostic testing: application for warfarin therapy. Clin Chem. 2009; 55(10): 1861-1868. [PubMed: 19679631]

56. Aithal GP, Day CP, Kesteven PJ, Daly AK. Association of polymorphisms in the cytochrome P450 CYP2C9 with warfarin dose requirement and risk of bleeding complications. Lancet. 1999; 353(9154):717-719. [PubMed: 10073515]

57. Furuya H, Fernandez-Salguero P, Gregory W, et al. Genetic polymorphism of CYP2C9 and its effect on warfarin maintenance dose requirement in patients undergoing anticoagulation therapy. Pharmacogenetics. 1995; 5(6):389-392. [PubMed: 8747411]

58. Higashi MK, Veenstra DL, Kondo LM, et al. Association between CYP2C9 genetic variants and anticoagulation-related outcomes during warfarin therapy. JAMA. 2002; 287(13):1690-1698. [PubMed: 11926893]

59. Hillman MA, Wilke RA, Caldwell MD, Berg RL, Glurich I, Burmester JK. Relative impact of covariates in prescribing warfarin according to CYP2C9 genotype. Pharmacogenetics. 2004; 14(8):539-547. [PubMed: 15284536]

60. Steward DJ, Haining RL, Henne KR, et al. Genetic association between sensitivity to warfarin and expression of CYP2C9*3. Pharmacogenetics. 1997; 7(5):361-367. [PubMed: 9352571] 
61. Imai J, Ieiri I, Mamiya K, et al. Polymorphism of the cytochrome P450 (CYP) 2C9 gene in Japanese epileptic patients: genetic analysis of the CYP2C9 locus. Pharmacogenetics. 2000; 10(1): 85-89. [PubMed: 10739176]

62. Cavallari LH, Langaee TY, Momary KM, et al. Genetic and clinical predictors of warfarin dose requirements in African Americans. Clin Pharmacol Ther. 2010; 87(4):459-464. [PubMed: 20072124]

63. Dickmann LJ, Rettie AE, Kneller MB, et al. Identification and functional characterization of a new CYP2C9 variant (CYP2C9*5) expressed among African Americans. Mol Pharmacol. 2001; 60(2): 382-387. [PubMed: 11455026]

64. Scott SA, Khasawneh R, Peter I, Kornreich R, Desnick RJ. Combined CYP2C9, VKORC1 and CYP4F2 frequencies among racial and ethnic groups. Pharmacogenomics. 2010; 11(6):781-791. [PubMed: 20504253]

65. DeLozier TC, Lee SC, Coulter SJ, Goh BC, Goldstein JA. Functional characterization of novel allelic variants of CYP2C9 recently discovered in southeast Asians. J Pharmacol Exp Ther. 2005; 315(3):1085-1090. [PubMed: 16099926]

66. Oldenburg J, Marinova M, Müller-Reible C, Watzka M. The vitamin K cycle. Vitam Horm. 2008; 78:35-62. [PubMed: 18374189]

67. Rasmussen MA, Skov J, Bladbjerg EM, Sidelmann JJ, Vamosi M, Jespersen J. Multivariate analysis of the relation between diet and warfarin dose. Eur J Clin Pharmacol. 2012; 68(3):321328. [PubMed: 21935704]

68. Ansell, J.; Hirsh, J.; Poller, L.; Bussey, H.; Jacobson, A.; Hylek, E. The pharmacology and management of the vitamin K antagonists. Chest; the Seventh ACCP Conference on Antithrombotic and Thrombolytic Therapy; 2004. p. 204S-233S.Erratum in Chest 2005;127(1): 415-416

69. Stafford DW. The vitamin K cycle. J Thromb Haemost. 2005; 3(8):1873-1878. [PubMed: 16102054]

70. Oldenburg J, Watzka M, Rost S, Müller CR. VKORC1: molecular target of coumarins. J Thromb Haemost. 2007; 5(Suppl 1):1-6. [PubMed: 17635701]

71. Wang D, Chen H, Momary KM, Cavallari LH, Johnson JA, Sadée W. Regulatory polymorphism in vitamin K epoxide reductase complex subunit 1 (VKORC1) affects gene expression and warfarin dose requirement. Blood. 2008; 112(4):1013-1021. [PubMed: 18523153]

72. Rost S, Fregin A, Ivaskevicius V, et al. Mutations in VKORC1 cause warfarin resistance and multiple coagulation factor deficiency type 2. Nature. 2004; 427(6974):537-541. [PubMed: 14765194]

73. Li T, Chang CY, Jin DY, Lin PJ, Khvorova A, Stafford DW. Identification of the gene for vitamin K epoxide reductase. Nature. 2004; 427(6974):541-544. [PubMed: 14765195]

74. Harrington DJ, Gorska R, Wheeler R, et al. Pharmacodynamic resistance to warfarin is associated with nucleotide substitutions in VKORC1. J Thromb Haemost. 2008; 6(10):1663-1670. [PubMed: 18680536]

75. Moreau C, Pautas E, Gouin-Thibault I, et al. Predicting the warfarin maintenance dose in elderly inpatients at treatment initiation: accuracy of dosing algorithms incorporating or not VKORC1/ CYP2C9 genotypes. J Thromb Haemost. 2011; 9(4):711-718. [PubMed: 21255252]

76. D'Andrea G, D'Ambrosio RL, Di Perna P, et al. A polymorphism in the VKORC1 gene is associated with an interindividual variability in the dose-anticoagulant effect of warfarin. Blood. 2005; 105(2):645-649. [PubMed: 15358623]

77. Loebstein R, Dvoskin I, Halkin H, et al. A coding VKORC1 Asp36Tyr polymorphism predisposes to warfarin resistance. Blood. 2007; 109(6):2477-2480. [PubMed: 17110455]

78. Marsh S, King CR, Porche-Sorbet RM, Scott-Horton TJ, Eby CS. Population variation in VKORC1 haplotype structure. J Thromb Haemost. 2006; 4(2):473-474. [PubMed: 16420583]

79. Watzka M, Geisen C, Bevans CG, et al. Thirteen novel VKORC1 mutations associated with oral anticoagulant resistance: insights into improved patient diagnosis and treatment. J Thromb Haemost. 2011; 9(1):109-118. [PubMed: 20946155] 
80. Aquilante CL, Langaee TY, Lopez LM, et al. Influence of coagulation factor, vitamin K epoxide reductase complex subunit 1 , and cytochrome P450 2C9 gene polymorphisms on warfarin dose requirements. Clin Pharmacol Ther. 2006; 79(4):291-302. [PubMed: 16580898]

81. Carlquist JF, Horne BD, Muhlestein JB, et al. Genotypes of the cytochrome p450 isoform, CYP2C9, and the vitamin K epoxide reductase complex subunit 1 conjointly determine stable warfarin dose: a prospective study. J Thromb Thrombolysis. 2006; 22(3):191-197. [PubMed: 17111199]

82. Pautas E, Moreau C, Gouin-Thibault I, et al. Genetic factors (VKORC1, CYP2C9, EPHX1, and CYP4F2) are predictor variables for warfarin response in very elderly, frail inpatients. Clin Pharmacol Ther. 2010; 87(1):57-64. [PubMed: 19794411]

83. Takanashi K, Tainaka H, Kobayashi K, Yasumori T, Hosakawa M, Chiba K. CYP2C9 Ile359 and Leu359 variants: enzyme kinetic study with seven substrates. Pharmacogenetics. 2000; 10(2):95104. [PubMed: 10761997]

84. Wadelius M, Chen LY, Downes K, et al. Common VKORC1 and GGCX polymorphisms associated with warfarin dose. Pharmacogenomics J. 2005; 5(4):262-270. [PubMed: 15883587]

85. Wadelius M, Sörlin K, Wallerman O, et al. Warfarin sensitivity related to CYP2C9, CYP3A5, ABCB1 (MDR1) and other factors. Pharmacogenomics J. 2004; 4(1):40-48. [PubMed: 14676821]

86. Cho HJ, On YK, Bang OY, et al. Development and comparison of a warfarin-dosing algorithm for Korean patients with atrial fibrillation. Clin Ther. 2011; 33(10):1371-1380. [PubMed: 21981797]

87. Lenzini P, Wadelius M, Kimmel S, et al. Integration of genetic, clinical, and INR data to refine warfarin dosing. Clin Pharmacol Ther. 2010; 87(5):572-578. [PubMed: 20375999]

88. Ferder NS, Eby CS, Deych E, et al. Ability of VKORC1 and CYP2C9 to predict therapeutic warfarin dose during the initial weeks of therapy. J Thromb Haemost. 2010; 8(1):95-100. [PubMed: 19874474]

89. González Della Valle A, Khakharia S, Glueck CJ, et al. VKORC1 variant genotypes influence warfarin response in patients undergoing total joint arthroplasty: a pilot study. Clin Orthop Relat Res. 2009; 467(7):1773-1780. [PubMed: 19034590]

90. Lazo-Langner A, Monkman K, Kovacs MJ. Predicting warfarin maintenance dose in patients with venous thromboembolism based on the response to a standardized warfarin initiation nomogram. $\mathbf{J}$ Thromb Haemost. 2009; 7(8):1276-1283. [PubMed: 19453939]

91. Marin-Leblanc M, Perreault S, Bahroun I, et al. Validation of warfarin pharmacogenetic algorithms in clinical practice. Pharmacogenomics. 2012; 13(1):21-29. [PubMed: 22176621]

92. Roper N, Storer B, Bona R, Fang M. Validation and comparison of pharmacogenetics-based warfarin dosing algorithms for application of pharmacogenetic testing. J Mol Diagn. 2010; 12(3): 283-291. [PubMed: 20228265]

93. Sasaki T, Tabuchi H, Higuchi S, Ieiri I. Warfarin-dosing algorithm based on a population pharmacokinetic/pharmacodynamic model combined with Bayesian forecasting. Pharmacogenomics. 2009; 10(8):1257-1266. [PubMed: 19663670]

94. Schwarz UI, Ritchie MD, Bradford Y, et al. Genetic determinants of response to warfarin during initial anticoagulation. N Engl J Med. 2008; 358(10):999-1008. [PubMed: 18322281]

95. Shaw PB, Donovan JL, Tran MT, Lemon SC, Burgwinkle P, Gore J. Accuracy assessment of pharmacogenetically predictive warfarin dosing algorithms in patients of an academic medical center anticoagulation clinic. J Thromb Thrombolysis. 2010; 30(2):220-225. [PubMed: 20204461]

96. Wells PS, Majeed H, Kassem S, et al. A regression model to predict warfarin dose from clinical variables and polymorphisms in CYP2C9, CYP4F2, and VKORC1: Derivation in a sample with predominantly a history of venous thromboembolism. Thromb Res. 2010; 125(6):e259-e264. [PubMed: 20421126]

97. Caraco Y, Blotnick S, Muszkat M. CYP2C9 genotype-guided warfarin prescribing enhances the efficacy and safety of anticoagulation: a prospective randomized controlled study. Clin Pharmacol Ther. 2008; 83(3):460-470. [PubMed: 17851566]

98. Eriksson N, Wadelius M. Prediction of warfarin dose: why, when and how? Pharmacogenomics. 2012; 13(4):429-440. [PubMed: 22379999] 
99. Lenzini PA, Grice GR, Milligan PE, et al. Laboratory and clinical outcomes of pharmacogenetic vs. clinical protocols for warfarin initiation in orthopedic patients. J Thromb Haemost. 2008; 6(10):1655-1662. [PubMed: 18662264]

100. Millican EA, Lenzini PA, Milligan PE, et al. Genetic-based dosing in orthopedic patients beginning warfarin therapy. Blood. 2007; 110(5):1511-1515. [PubMed: 17387222]

101. Voora D, McLeod HL, Eby C, Gage BF. The pharmacogenetics of coumarin therapy. Pharmacogenomics. 2005; 6(5):503-513. [PubMed: 16014000]

102. Wen MS, Lee M, Chen JJ, et al. Prospective study of warfarin dosage requirements based on CYP2C9 and VKORC1 genotypes. Clin Pharmacol Ther. 2008; 84(1):83-89. [PubMed: 18183038]

103. Connolly SJ, Pogue J, Eikelboom J, et al. Benefit of oral anticoagulant over antiplatelet therapy in atrial fibrillation depends on the quality of international normalized ratio control achieved by centers and countries as measured by time in therapeutic range. Circulation. 2008; 118(20):20292037. [PubMed: 18955670]

104. Horne BD, Lenzini PA, Wadelius M, et al. Pharmacogenetic warfarin dose refinements remain significantly influenced by genetic factors after one week of therapy. Thromb Haemost. 2012; 107(2):232-240. [PubMed: 22186998]

105. Burmester JK, Berg RL, Yale SH, et al. A randomized controlled trial of genotype-based Coumadin initiation. Genet Med. 2011; 13(6):509-518. [PubMed: 21423021]

106. McMillin GA, Melis R, Wilson A, et al. Gene-based warfarin dosing compared with standard of care practices in an orthopedic surgery population: a prospective, parallel cohort study. Ther Drug Monit. 2010; 32(3):338-345. [PubMed: 20386359]

107. Carlquist JF, Anderson JL. Using pharmacogenetics in real time to guide warfarin initiation: a clinician update. Circulation. 2011; 124(23):2554-2559. [PubMed: 22144632]

108. Limdi NA, Wiener H, Goldstein JA, Acton RT, Beasley TM. Influence of CYP2C9 and VKORC1 on warfarin response during initiation of therapy. Blood Cells Mol Dis. 2009; 43(1): 119-128. [PubMed: 19297219]

109. Schelleman H, Limdi NA, Kimmel SE. Ethnic differences in warfarin maintenance dose requirement and its relationship with genetics. Pharmacogenomics. 2008; 9(9):1331-1346. [PubMed: 18781859]

110. Yang L, Ge W, Yu F, Zhu H. Impact of VKORC1 gene polymorphism on interindividual and interethnic warfarin dosage requirement - a systematic review and meta analysis. Thromb Res. 2010; 125(4):e159-e166. [PubMed: 19942260]

111. Campbell MC, Tishkoff SA. African genetic diversity: implications for human demographic history, modern human origins, and complex disease mapping. Annu Rev Genomics Hum Genet. 2008; 9:403-433. [PubMed: 18593304]

112. Ramirez AH, Shi Y, Schildcrout JS, et al. Predicting warfarin dosage in European-Americans and African-Americans using DNA samples linked to an electronic health record. Pharmacogenomics. 2012; 13(4):407-418. [PubMed: 22329724]

113. Limdi NA, McGwin G, Goldstein JA, et al. Influence of CYP2C9 and VKORC1 1173C/T genotype on the risk of hemorrhagic complications in African-American and European-American patients on warfarin. Clin Pharmacol Ther. 2008; 83(2):312-321. [PubMed: 17653141]

114. Momary KM, Shapiro NL, Viana MA, Nutescu EA, Helgason CM, Cavallari LH. Factors influencing warfarin dose requirements in African-Americans. Pharmacogenomics. 2007; 8(11): 1535-1544. [PubMed: 18034618]

115. Limdi NA, Beasley TM, Crowley MR, et al. VKORC1 polymorphisms, haplotypes and haplotype groups on warfarin dose among African-Americans and European-Americans. Pharmacogenomics. 2008; 9(10):1445-1458. [PubMed: 18855533]

116. Shrif NE, Won HH, Lee ST, et al. Evaluation of the effects of VKORC1 polymorphisms and haplotypes, CYP2C9 genotypes, and clinical factors on warfarin response in Sudanese patients. Eur J Clin Pharmacol. 2011; 67(11):1119-1130. [PubMed: 21590310]

117. Mitchell C, Gregersen N, Krause A. Novel CYP2C9 and VKORC1 gene variants associated with warfarin dosage variability in the South African black population. Pharmacogenomics. 2011; 12(7):953-963. [PubMed: 21635147] 
118. Dandara C, Lombard Z, Du Plooy I, McLellan T, Norris SA, Ramsay M. Genetic variants in CYP $(-1 \mathrm{~A} 2,-2 \mathrm{C} 9,-2 \mathrm{C} 19,-3 \mathrm{~A} 4$ and $-3 \mathrm{~A} 5)$, VKORC1 and ABCB1 genes in a black South African population: a window into diversity. Pharmacogenomics. 2011; 12(12):1663-1670. [PubMed: 22118051]

119. Aklillu E, Leong C, Loebstein R, Halkin H, Gak E. VKORC1 Asp36Tyr warfarin resistance marker is common in Ethiopian individuals. Blood. 2008; 111(7):3903-3904. [PubMed: 18362220]

120. Kimura R, Miyashita K, Kokubo Y, et al. Genotypes of vitamin K epoxide reductase, gammaglutamyl carboxylase, and cytochrome P450 2C9 as determinants of daily warfarin dose in Japanese patients. Thromb Res. 2007; 120(2):181-186. [PubMed: 17049586]

121. Miyagata Y, Nakai K, Sugiyama Y. Clinical significance of combined CYP2C9 and VKORC1 genotypes in Japanese patients requiring warfarin. Int Heart J. 2011; 52(1):44-49. [PubMed: 21321468]

122. Yu HC, Chan TY, Critchley JA, Woo KS. Factors determining the maintenance dose of warfarin in Chinese patients. QJM. 1996; 89(2):127-135. [PubMed: 8729554]

123. Lee MT, Chen $\mathrm{CH}$, Chuang HP, et al. VKORC1 haplotypes in five East-Asian populations and Indians. Pharmacogenomics. 2009; 10(10):1609-1616. [PubMed: 19842934]

124. Choi JR, Kim JO, Kang DR, et al. Proposal of pharmacogenetics-based warfarin dosing algorithm in Korean patients. J Hum Genet. 2011; 56(4):290-295. [PubMed: 21326313]

125. Zeng WT, Zheng QS, Huang M, et al. Genetic polymorphisms of VKORC1, CYP2C9, CYP4F2 in Bai, Tibetan Chinese. Pharmazie. 2012; 67(1):69-73. [PubMed: 22393834]

126. Ohno M, Yamamoto A, Ono A, et al. Influence of clinical and genetic factors on warfarin dose requirements among Japanese patients. Eur J Clin Pharmacol. 2009; 65(11):1097-1103. [PubMed: 19582440]

127. Gu Q, Kong Y, Schneede J, et al. VKORC1-1639G > A, CYP2C9, EPHX1691A > G genotype, body weight, and age are important predictors for warfarin maintenance doses in patients with mechanical heart valve prostheses in southwest China. Eur J Clin Pharmacol. 2010; 66(12):12171227. [PubMed: 20842355]

128. Huang SW, Chen HS, Wang XQ, et al. Validation of VKORC1 and CYP2C9 genotypes on interindividual warfarin maintenance dose: a prospective study in Chinese patients. Pharmacogenet Genomics. 2009; 19(3):226-234. [PubMed: 19177029]

129. Kim HS, Lee SS, Oh M, et al. Effect of CYP2C9 and VKORC1 genotypes on early-phase and steady-state warfarin dosing in Korean patients with mechanical heart valve replacement. Pharmacogenet Genomics. 2009; 19(2):103-112. [PubMed: 19077919]

130. Lee MT, Chen $\mathrm{CH}$, Chou $\mathrm{CH}$, et al. Genetic determinants of warfarin dosing in the Han-Chinese population. Pharmacogenomics. 2009; 10(12):1905-1913. [PubMed: 19958090]

131. Liang R, Li L, Li C, et al. Impact of CYP2C9*3, VKORC1-1639, CYP4F2rs2108622 genetic polymorphism and clinical factors on warfarin maintenance dose in Han-Chinese patients. $\mathrm{J}$ Thromb Thrombolysis. 2012; 34(1):120-125. [PubMed: 22528326]

132. Miao L, Yang J, Huang C, Shen Z. Contribution of age, body weight, and CYP2C9 and VKORC1 genotype to the anticoagulant response to warfarin: proposal for a new dosing regimen in Chinese patients. Eur J Clin Pharmacol. 2007; 63(12):1135-1141. [PubMed: 17899045]

133. Wang TL, Li HL, Tjong WY, et al. Genetic factors contribute to patient-specific warfarin dose for Han Chinese. Clin Chim Acta. 2008; 396(1-2):76-79. [PubMed: 18680736]

134. Yang J, Huang C, Shen Z, Miao L. Contribution of $1173 \mathrm{C}>\mathrm{T}$ polymorphism in the VKORC1 gene to warfarin dose requirements in Han Chinese patients receiving anticoagulation. Int J Clin Pharmacol Ther. 2011; 49(1):23-29. [PubMed: 21176721]

135. Yoshizawa M, Hayashi H, Tashiro Y, et al. Effect of VKORC1-1639 G > A polymorphism, body weight, age, and serum albumin alterations on warfarin response in Japanese patients. Thromb Res. 2009; 124(2):161-166. [PubMed: 19135231]

136. You JH, Wong RS, Waye MM, et al. Warfarin dosing algorithm using clinical, demographic and pharmacogenetic data from Chinese patients. J Thromb Thrombolysis. 2011; 31(1):113-118. [PubMed: 20585834] 
137. Zhang W, Zhang WJ, Zhu J, et al. Genetic polymorphisms are associated with variations in warfarin maintenance dose in Han Chinese patients with venous thromboembolism.

Pharmacogenomics. 2012; 13(3):309-321. [PubMed: 22248286]

138. Lee SC, Ng SS, Oldenburg J, et al. Interethnic variability of warfarin maintenance requirement is explained by VKORC1 genotype in an Asian population. Clin Pharmacol Ther. 2006; 79(3):197205. [PubMed: 16513444]

139. Sangviroon A, Panomvana D, Tassaneeyakul W, Namchaisiri J. Pharmacokinetic and pharmacodynamic variation associated with VKORC1 and CYP2C9 polymorphisms in Thai patients taking warfarin. Drug Metab Pharmacokinet. 2010; 25(6):531-538. [PubMed: 20930419]

140. Zhao F, Loke C, Rankin SC, et al. Novel CYP2C9 genetic variants in Asian subjects and their influence on maintenance warfarin dose. Clin Pharmacol Ther. 2004; 76(3):210-219. [PubMed: 15371982]

141. Pavani A, Naushad SM, Rupasree Y, et al. Optimization of warfarin dose by population-specific pharmacogenomic algorithm. Pharmacogenomics J. 2012; 12(4):306-311. [PubMed: 21358752]

142. Rathore SS, Agarwal SK, Pande S, Mittal T, Mittal B. Frequencies of VKORC1 -1639 G > A, CYP2C9*2 and CYP2C9*3 genetic variants in the Northern Indian population. Biosci Trends. 2010; 4(6):333-337. [PubMed: 21248432]

143. Suriapranata IM, Tjong WY, Wang T, et al. Genetic factors associated with patient-specific warfarin dose in ethnic Indonesians. BMC Med Genet. 2011; 12:80. [PubMed: 21639946]

144. Teh LK, Langmia IM, Fazleen Haslinda MH, et al. Clinical relevance of VKORC1 (G-1639A and C1173T) and CYP2C9*3 among patients on warfarin. J Clin Pharm Ther. 2012; 37(2):232-236. [PubMed: 21507031]

145. Perini JA, Petzl-Erler ML, Tsuneto LT, Suarez-Kurtz G. VKORC1 polymorphisms in Amerindian populations of Brazil. Pharmacogenomics. 2008; 9(11):1623-1629. [PubMed: 19018718]

146. Botton MR, Bandinelli E, Rohde LE, Amon LC, Hutz MH. Influence of genetic, biological and pharmacological factors on warfarin dose in a Southern Brazilian population of European ancestry. Br J Clin Pharmacol. 2011; 72(3):442-450. [PubMed: 21320153]

147. Scibona P, Redal MA, Garfi LG, Arbelbide J, Argibay PF, Belloso WH. Prevalence of CYP2C9 and VKORC1 alleles in the Argentine population and implications for prescribing dosages of anticoagulants. Genet Mol Res. 2012; 11(1):70-76. [PubMed: 22290467]

148. Cavallari LH, Momary KM, Patel SR, Shapiro NL, Nutescu E, Viana MA. Pharmacogenomics of warfarin dose requirements in Hispanics. Blood Cells Mol Dis. 2011; 46(2):147-150. [PubMed: 21185752]

149. Palacio L, Falla D, Tobon I, et al. Pharmacogenetic impact of VKORC1 and CYP2C9 allelic variants on warfarin dose requirements in a Hispanic population isolate. Clin Appl Thromb Hemost. 2010; 16(1):83-90. [PubMed: 19567378]

150. Valentin II, Vazquez J, Rivera-Miranda G, et al. Prediction of warfarin dose reductions in Puerto Rican patients, based on combinatorial CYP2C9 and VKORC1 genotypes. Ann Pharmacother. 2012; 46(2):208-218. [PubMed: 22274142]

151. Villagra D, Duconge J, Windemuth A, et al. CYP2C9 and VKORC1 genotypes in Puerto Ricans: a case for admixture-matching in clinical pharmacogenetic studies. Clin Chim Acta. 2010; 411(17-18):1306-1311. [PubMed: 20488169]

152. Oner Ozgon G, Langaee TY, Feng H, et al. VKORC1 and CYP2C9 polymorphisms are associated with warfarin dose requirements in Turkish patients. Eur J Clin Pharmacol. 2008; 64(9):889-894. [PubMed: 18542936]

153. Ozer N, Cam N, Tangurek B, et al. The impact of CYP2C9 and VKORC1 genetic polymorphism and patient characteristics upon warfarin dose requirements in an adult Turkish population. Heart Vessels. 2010; 25(2):155-162. [PubMed: 20339978]

154. Djaffar-Jureidini I, Chamseddine N, Keleshian S, Naoufal R, Zahed L, Hakime N. Pharmacogenetics of coumarin dosing: prevalence of CYP2C9 and VKORC1 polymorphisms in the Lebanese population. Genet Test Mol Biomarkers. 2011; 15(11):827-830. [PubMed: 21651319] 
155. Esmerian MO, Mitri Z, Habbal MZ, et al. Influence of CYP2C9 and VKORC1 polymorphisms on warfarin and acenocoumarol in a sample of Lebanese people. J Clin Pharmacol. 2011; 51(10): 1418-1428. [PubMed: 21148049]

156. Pathare AV, Al Zadjali S, Misquith R, et al. Warfarin pharmacogenetics: polymorphisms of the CYP2C9, CYP4F2, and VKORC1 loci in a genetically admixed Omani population. Hum Biol. 2012; 84(1):67-77. [PubMed: 22452429]

157. El Din MS, Amin DG, Ragab SB, Ashour EE, Mohamed MH, Mohamed AM. Frequency of VKORC1 (C1173T) and CYP2C9 genetic polymorphisms in Egyptians and their influence on warfarin maintenance dose: proposal for a new dosing regimen. Int J Lab Hematol. 2012; 34(5): 517-524. [PubMed: 22533669]

158. Shahin MH, Khalifa SI, Gong Y, et al. Genetic and nongenetic factors associated with warfarin dose requirements in Egyptian patients. Pharmacogenet Genomics. 2011; 21(3):130-135. [PubMed: 21228733]

159. Scott SA, Edelmann L, Kornreich R, Desnick RJ. Warfarin pharmacogenetics: CYP2C9 and VKORC1 genotypes predict different sensitivity and resistance frequencies in the Ashkenazi and Sephardi Jewish populations. Am J Hum Genet. 2008; 82(2):495-500. [PubMed: 18252229]

160. Cha PC, Mushiroda T, Takahashi A, et al. Genome-wide association study identifies genetic determinants of warfarin responsiveness for Japanese. Hum Mol Genet. 2010; 19(23):47354744. [PubMed: 20833655]

161. Jorgensen AL, Al-Zubiedi S, Zhang JE, et al. Genetic and environmental factors determining clinical outcomes and cost of warfarin therapy: a prospective study. Pharmacogenet Genomics. 2009; 19(10):800-812. [PubMed: 19752777]

162. Lango AH, Estrada K, Lettre G, et al. Hundreds of variants clustered in genomic loci and biological pathways affect human height. Nature. 2010; 467(7317):832-838. [PubMed: 20881960]

163. Cardon LR, Palmer LJ. Population stratification and spurious allelic association. Lancet. 2003; 361(9357):598-604. [PubMed: 12598158]

164. Marchini J, Cardon LR, Phillips MS, Donnelly P. The effects of human population structure on large genetic association studies. Nat Genet. 2004; 36(5):512-517. [PubMed: 15052271]

165. Bloss CS, Darst BF, Topol EJ, Schork NJ. Direct-to-consumer personalized genomic testing. Hum Mol Genet. 2011; 20(R2):R132-R141. [PubMed: 21828075]

166. Carlquist JF, McKinney JT, Nicholas ZP, et al. Rapid melting curve analysis for genetic variants that underlie inter-individual variability in stable warfarin dosing. J Thromb Thrombolysis. 2008; 26(1):1-7. [PubMed: 17661181]

167. Patrick AR, Avorn J, Choudhry NK. Cost-effectiveness of genotype-guided warfarin dosing for patients with atrial fibrillation. Circ Cardiovasc Qual Outcomes. 2009; 2(5):429_436. [PubMed: 20031873]

168. Teichert M, Eijgelsheim M, Rivadeneira F, et al. A genome-wide association study of acenocoumarol maintenance dosage. Hum Mol Genet. 2009; 18(19):3758-3768. [PubMed: 19578179] 


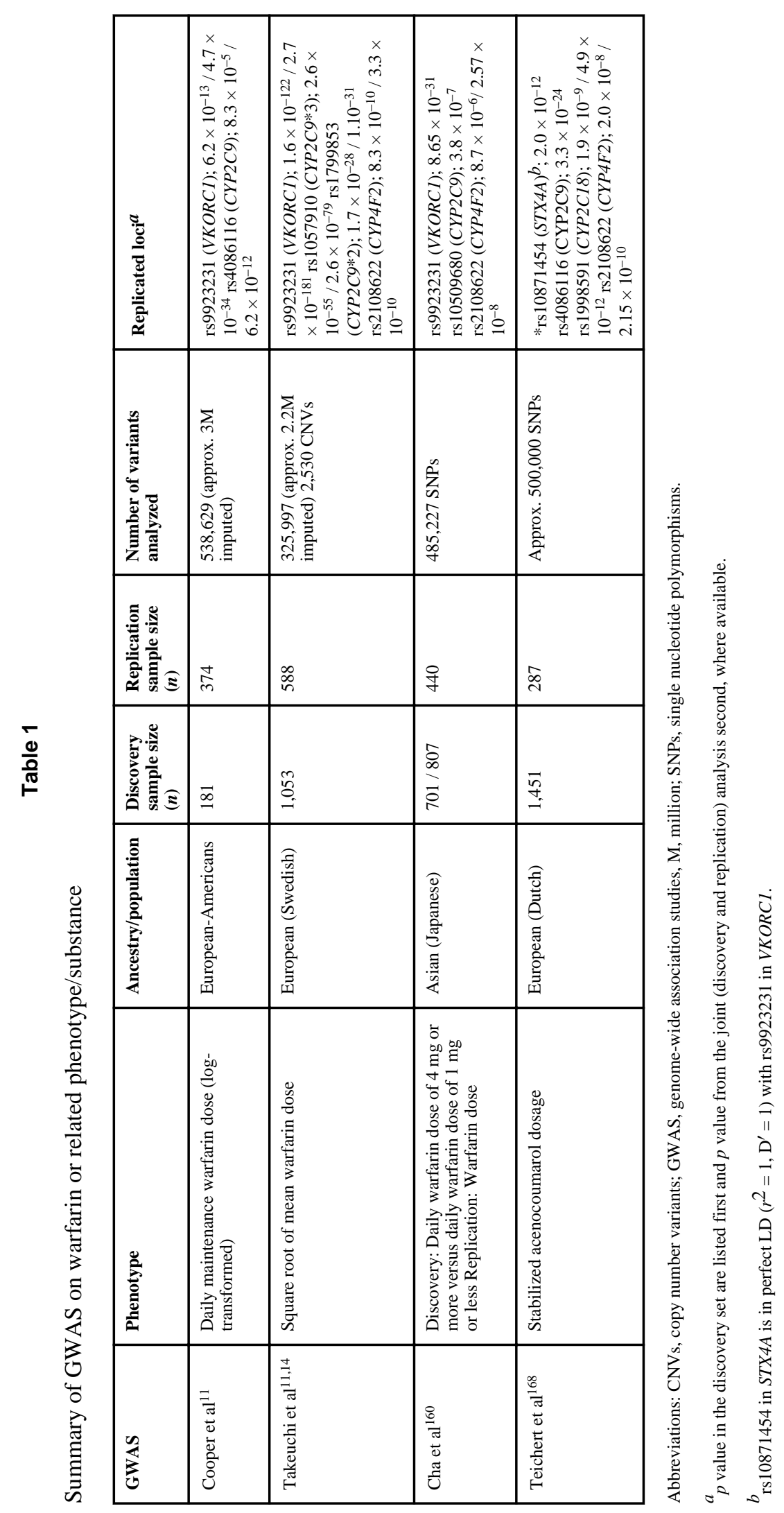

